\title{
Artemin and its emerging role in pathogenesis of systemic tumors besides pancreatic cancers
}

\section{Shailendra Kapoor*}

University of Illinois at Chicago, Chicago, IL, USA

*Correspondence: shailendrakapoor@yahoo.com

Edited by:

Yunfeng Cui, Tianjin Medical University, China

Reviewed by:

Yunfeng Cui, Tianjin Medical University, China

\section{A commentary on}

Nerve-cancer interactions in the stromal biology of pancreatic cancer

by Demir, I. E., Friess, H., and Ceyhan, G. O. (2012). Front. Physio. 3:97. doi: 10.3389/ fphys.2012.00097

TO THE EDITOR: The recent article by Demir et al. (2012) in your esteemed journal provided for highly stimulating and interesting reading. Interestingly, over the past few years artemin has been identified as a significant player in the enhancement of oncogenicity of various other tumors besides pancreatic cancers.

For instance, artemin enhances transcription of bcl2 - leading to it's up regulation and thereby augments tumor growth in human non-small cell lung carcinomas (Tang et al., 2010). Similarly, in estrogen receptor negative breast carcinomas, artemin shows synergization with TWIST 1 and thereby accentuates the metastatic potential of the primary breast tumor (Banerjee et al., 2011). As a result, a poor clinical outcome is associated with this combination of artemin and TWIST1. Attenuated artemin expression is seen as a result of tamoxifen administration (Kang et al., 2010). Interestingly, the sensitivity to tamoxifen of tamoxifen resistant mammary tissue is accentuated following antibody mediated inhibition of artemin.

Increased expression of artemin is also seen in esophageal carcinomas. Interestingly transfection with a mir-223 vector decreases expression of artemin and thereby suppresses tumor growth in esophageal carcinomas (Li et al., 2011). Similarly, artemin augments the expression of AKT1 and thereby accentuates the invasive potential of endometrial carcinomas (Pandey et al., 2010). The invasive potential of endometrial cancer tissue is significantly abrogated following antibody mediated inhibition of artemin.

The above examples clearly illustrate the significant enhancement of oncogenicity secondary to artemin in tumors ranging from lung carcinomas to endometrial carcinomas. There is a clear and urgent need to identify inhibitors of artemin function in order to improve the prognosis in these tumors.

\section{REFERENCES}

Banerjee, A., Wu, Z. S., Qian, P., Kang, J., Pandey, V., Liu, D. X., Zhu, T., and Lobie, P. E. (2011). Artemin synergizes with TWIST1 to promote metastasis and poor survival outcome in patients with ER negative mammary carcinoma. Breast Cancer Res. 13, R112.
Demir, I. E., Friess, H., and Ceyhan, G. O. (2012). Nerve-cancer interactions in the stromal biology of pancreatic cancer. Front. Physio. 3:97. doi: 10.3389/ fphys.2012.00097

Kang, J., Qian, P. X., Pandey, V., Perry, J. K., Miller, L. D., Liu, E. T., Zhu, T., Liu, D. X., and Lobie, P. E. (2010). Artemin is estrogen regulated and mediates antiestrogen resistance in mammary carcinoma. Oncogene 29, 3228-3240.

Li, S., Li, Z., Guo, F., Qin, X., Liu, B., Lei, Z., Song, Z., Sun, L., Zhang, H. T., You, J., and Zhou, Q. (2011). miR-223 regulates migration and invasion by targeting artemin in human esophageal carcinoma. J. Biomed. Sci. 18, 24

Pandey, V., Qian, P. X., Kang, J., Perry, J. K., Mitchell, M. D., Yin, Z., Wu, Z. S., Liu, D. X., Zhu, T., and Lobie, P. E. (2010). Artemin stimulates oncogenicity and invasiveness of human endometrial carcinoma cells. Endocrinology 151, 909-920.

Tang, J. Z., Kong, X. J., Kang, J., Fielder, G. C., Steiner, M., Perry, J. K., Wu, Z. S., Yin, Z., Zhu, T., Liu, D. X., and Lobie, P. E. (2010). Artemin-stimulated progression of human non-small cell lung carcinoma is mediated by BCL2. Mol. Cancer Ther. 9, 1697-1708.

Received: 19 July 2012; accepted: 20 July 2012; published online: 08 August 2012.

Citation: Kapoor S (2012) Artemin and its emerging role in pathogenesis of systemic tumors besides pancreatic cancers. Front. Oncol. 2:92. doi: 10.3389/fonc.2012.00092

This article was submitted to Frontiers in Gastrointestinal Cancers, a specialty of Frontiers in Oncology.

Copyright (c) 2012 Kapoor. This is an open-access article distributed under the terms of the Creative Commons Attribution License, which permits use, distribution and reproduction in other forums, provided the original authors and source are credited and subject to any copyright notices concerning any third-party graphics etc. 